\title{
Characterization of Carbon Felt Electrodes for Vanadium Redox Flow Batteries: Impact of Treatment Methods
}

\author{
L. Eifert, ${ }^{1, *}$ R. Banerjee, $\oplus^{1}$ Z. Jusys, $\oplus^{2, * *}$ and R. Zeis $\oplus^{1,3, z}$ \\ ${ }^{1}$ Karlsruhe Institute of Technology, Helmholtz Institute Ulm, 89081 Ulm, Germany \\ ${ }^{2}$ Institute of Surface Chemistry and Catalysis, Ulm University, 89081 Ulm, Germany \\ ${ }^{3}$ Karlsruhe Institute of Technology, Institute of Physical Chemistry, 76131 Karlsruhe, Germany
}

\begin{abstract}
In this study, we investigated the influence of thermal treatment, soaking in $\mathrm{H}_{2} \mathrm{SO}_{4}$ and electrochemical ageing on commercially available carbon felt materials from SGL carbon. We compared both the influence of the pre-treatment (carbonization or graphitization) and the influence of the precursor (Rayon or PAN). By thermogravimetric analysis coupled with mass spectrometry (TGA-MS) we showed, that after thermal treatment, the thermal stability was lower for carbonized felts compared to graphitized felts and the Rayon based felts were more stable than PAN based ones. Soaking had a stronger impact on the thermal stability of PAN based felts, whereas it was similar to the electrochemical ageing for Rayon based felts. X-ray photoelectron spectroscopy and Raman spectroscopy revealed that thermal treatment reduces the overall surface oxygen content for all felt types and the degree of graphitization doesn't change, but the content of single bonded oxygen was increased for graphitized carbon felts, only. For carbonized felts, thermal treatment highly reduced the electrochemical activity characterized by cyclic voltammetry due to a reduced overall oxygen content and increased $\mathrm{C}=\mathrm{O}$ and $\mathrm{C}=\mathrm{C}$ contents. In this work, we provide a comprehensive overview of commercially available carbon felts and characterize the effects of several treatment methods.

(C) The Author(s) 2018. Published by ECS. This is an open access article distributed under the terms of the Creative Commons Attribution 4.0 License (CC BY, http://creativecommons.org/licenses/by/4.0/), which permits unrestricted reuse of the work in any medium, provided the original work is properly cited. [DOI: $10.1149 / 2.0531811 \mathrm{jes}]$

(cc) BY
\end{abstract}

Manuscript submitted June 8, 2018; revised manuscript received July 26, 2018. Published August 21, 2018.

By nature, many renewable energy sources like wind and solar power plants have a fluctuating energy output. Redox flow batteries (RFBs) are a promising technology to compensate and stabilize the power grid. ${ }^{1-4}$ All-Vanadium redox flow batteries (VRFBs) are the most common, well studied redox flow battery type since its development in the late 1980s by Skyllas-Kazacos. ${ }^{2,5}$

The electrodes are a crucial part of the VRFB, since its chemical, physical and structural properties affect parameters like cell performance, efficiency, durability and even acquisition and operating costs. $^{6-9}$ The most common electrode materials are carbonized or graphitized polyacrylamide (PAN) or Rayon (cellulose) fibers and are commercially available as paper or felts. Due to its relatively low activity toward the redox reactions of vanadium and poor wettability, several approaches have been made to improve the properties of the electrodes.

These include improved felt design, ${ }^{10-13}$ compression, ${ }^{14-16}$ as well as surface modifications, which either increase the surface area, ${ }^{17-21}$ or introduce functional groups ${ }^{22-28}$ or supporting catalysts, such as metals ${ }^{29,30}$ or metal oxides. ${ }^{31-33}$ So far, the most practical and common treatment method is a thermal treatment, where the electrode surface is oxidized in an air atmosphere for up to $30 \mathrm{~h}$ at $400^{\circ} \mathrm{C} .{ }^{34-36}$

Although most publications are focusing on one carbon felt or paper type and their modification, the precursor was found to influence the catalytic activity of the electrode. Zhong et al. studied the differences between Rayon and PAN based graphite electrodes with regard to electrical resistivity, pore size and surface area, as well as the interaction of surface atoms by means of X-ray photoelectron spectroscopy (XPS) and surface morphology by means of scanning electron microscopy (SEM). They found a higher electrical conductivity as well as a higher resistance to oxidation for PAN based electrodes and suggested that these differences originate in their microstructure. ${ }^{37}$ Schweiss et al. investigated the parasitic hydrogen evolution, which takes place at potentials close to the $\mathrm{V}^{2+} / \mathrm{V}^{3+}$ redox potentials, on Rayon and PAN based carbon felts before and after thermal surface oxidation in air at $750^{\circ} \mathrm{C}$ for 5 minutes. They found a higher hydrogen evolution rate for PAN-based felts compared to Rayon-based carbon felts and attributed it to the higher amount of nitrogen containing functional groups. ${ }^{38}$ The study by

\footnotetext{
*Electrochemical Society Student Member.

**Electrochemical Society Member.

${ }^{\mathrm{z}}$ E-mail: roswitha.zeis@kit.edu
}

Fink et al. compared PAN and Rayon based, graphitized felts and their electrochemical properties and found, that the electrochemical activity toward $\mathrm{V}^{2+} / \mathrm{V}^{3+}$ and $\mathrm{V}^{4+} / \mathrm{V}^{5+}$ redox couples are dependent on the electrode material and their treatment method prior to the measurement. ${ }^{39}$

One of the major reasons of overall performance losses of the VRFB can be attributed to the degradation of the electrodes due to side reactions. ${ }^{40,41}$ Besides the hydrogen evolution on the negative electrode of the VRFB, carbon corrosion can take place on the positive electrode. Since the $\mathrm{V}^{4+} / \mathrm{V}^{5+}$ redox couple has a standard oxidation potential of $\mathrm{E}_{0}=1.00 \mathrm{~V}$, the oxidation reactions to $\mathrm{CO}_{2}$ and $\mathrm{CO}$ are competing with the desired reaction, due to their standard oxidation potentials of $0.207 \mathrm{~V}$ and $0.518 \mathrm{~V}$, respectively. ${ }^{42}$ However, due to their slow kinetics, the oxidation of vanadium (IV) to vanadium (V) is still favoured, unless large overpotentials are applied or most of the vanadium is already oxidized (e.g. the state of charge of the VRFB is close to $100 \%) .{ }^{43,44}$ During degradation, surface functional groups are removed and therefore may cause a loss of electrochemically active surface area. ${ }^{41,45}$

To provide a comprehensive overview on the chemical and electrochemical properties and thermal stability of commercially available Rayon and PAN based carbon felts from SGL Carbon (Meitingen, Germany), we developed a stress test. In this stress test, the electrodes undergo extreme conditions to ensure an accelerated ageing process. We studied the influence of thermal treatment, soaking in sulfuric acid as sole chemical ageing, as well as a combined chemical and electrochemical ageing on commercially available Rayon and PAN based carbon felts from SGL Carbon (Meitingen, Germany). Although the treatment methods were studied to some extent in literature, this work combines several characterization techniques and provides a comprehensive overview of three separate commercially available carbon felt electrodes by linking the results. This would allow for a good baseline comparison point for the redox flow community to compare their electrode materials to. The addition of the degradation mechanisms being investigated further provides data on the thermal, chemical, and electrochemical stability of these materials, also as a comparison for new electrode materials to be compared to.

We characterized all felts before and after treatment using scanning electron microscopy (SEM), thermogravimetric analysis coupled with mass spectrometry (TGA-MS), Raman spectroscopy, X-ray photoelectron spectroscopy (XPS) and cyclic voltammetry. 
Table I. Carbon felt types and their properties.

\begin{tabular}{|c|c|c|c|c|c|}
\hline Carbon felt & Precursor & Pre-treatment & $\begin{array}{c}\text { Nominal } \\
\text { thickness }[\mathrm{mm}]\end{array}$ & $\begin{array}{l}\text { Compression rate } \\
\text { in electrochemical } \\
\text { measurements [\%] }\end{array}$ & $\begin{array}{c}\text { Surface area in } \\
\text { electrochemical } \\
\text { measurements }\left[\mathrm{cm}^{2}\right]\end{array}$ \\
\hline GFA 6 EA & Rayon & Graphitized & 6 & 70 & 2.72 \\
\hline GFD $4.6 \mathrm{EA}$ & PAN & Graphitized & 4.6 & 61 & 2.72 \\
\hline KFD $2.5 \mathrm{EA}$ & PAN & Carbonized & 2.5 & 64 & 2.36 \\
\hline
\end{tabular}

\section{Methodology}

Materials and processing.-In all the experiments, the three types of commercially available SIGRACELL carbon felts by SGL Carbon (Meitingen, Germany) were studied. Table I summarizes the three felts and their properties.

Vanadium (IV) electrolytes were freshly prepared by dissolving $0.1 \mathrm{M} \mathrm{VOSO}_{4}\left(\mathrm{VOSO}_{4} \cdot 5 \mathrm{H}_{2} \mathrm{O}\right.$, chemically pure, GfE) in $2 \mathrm{M} \mathrm{H}_{2} \mathrm{SO}_{4}$ (Suprapur, Merck), while vanadium (V) electrolytes were produced right before being used by charging the aforementioned vanadium (IV) electrolyte by means of a VRFB in a redox flow test system (Scribner 857 test stand, Scribner Associates, North Carolina, USA) until a charging current of $2 \mathrm{~mA} / \mathrm{cm}^{2}$ was reached, where the battery is considered fully charged. 8,46

All three types of felt materials underwent specific treatments which impact their physical and chemical properties:

- A thermal treatment process at $400^{\circ} \mathrm{C}$ for $25 \mathrm{~h}$ in an air atmosphere to introduce active sites as described before in the literature..$^{34,35}$

- A soaking procedure, where the felt was stored in $4 \mathrm{M} \mathrm{H}_{2} \mathrm{SO}_{4}$ (Technical, VWR) at $40^{\circ} \mathrm{C}$ for $15 \mathrm{~d}$, which provides an insight into the influence of chemical ageing. ${ }^{8,41,47}$ These parameters were chosen to mimic typical full cell cycling conditions, but without the influence of vanadium and any applied potential.

- An ageing treatment, where a potential of $1.2 \mathrm{~V}$ vs. RHE was applied to the felt in a vanadium (V) electrolyte $(0.1 \mathrm{M} \mathrm{V}(\mathrm{V})$ in $2 \mathrm{M}$ $\mathrm{H}_{2} \mathrm{SO}_{4}$ ) for $5 \mathrm{~d}$. The potential and electrolyte are chosen for the halfcell reaction to comply with the positive electrode side of a fully charged VRFB, which induces a high stress on the electrodes. ${ }^{8,41,48}$

After both ageing processes the felts were rinsed and flushed with purified water $(18.2 \mathrm{M} \Omega \cdot \mathrm{cm})$ for at least 24 hours and dried before any further analysis. The dilution and diffusion driven removal of the sulfuric acid is assumed to be complete within this time. The samples in this study were labelled as non-activated/pristine, thermal, soaked, and aged corresponding to their treatment.

Scanning electron microscopy (SEM).- To investigate the surface morphology of the felt materials, a scanning electron microscope (SmartSEM Supra 55VP, Carl Zeiss SMT Ltd.) was utilized. The acceleration voltage was $3-6 \mathrm{kV}$ and a SE2 detector was used to obtain more details of the surface structure. SEM images were obtained at several magnifications to investigate features at the micro and nanoscales.

Thermogravimetric analysis/mass spectrometry (TGA-MS).-A thermogravimetric analyzer (Netzsch, TG 209 F1 Libra) coupled with a mass spectrometer (Netzsch, QMS 403 D Aëolos) was utilized to investigate the thermal stability of the felts. After an equilibration phase of $30 \mathrm{~min}$ at $35^{\circ} \mathrm{C}$ a temperature ramp of $5^{\circ} \mathrm{C} / \mathrm{min}$ was applied until $600^{\circ} \mathrm{C}$ was reached. During that ramp, any changes in weight were recorded while detecting volatile components of the sample in the gas stream by means of mass spectrometry. The system was continuously purged with Argon during the whole process. To improve the visibility of the trends in mass spectra, we applied a locally weighted scatterplot smoothing (LOWESS) with a Points of Window of 10 for the $\mathrm{SO}_{2}$ signal and 0.1 for all other signals. Additionally, we normalized the mass spectra to the initial sample weight to provide comparable signals within one felt type.

Raman spectroscopy.-To gain more insight regarding the surface defects of the respective felts, we utilized a Raman microscope (inVia, Renishaw) with a He-Ne-Laser $(633 \mathrm{~nm})$ and a 50x optical lens. The spectra were recorded between $3000 \mathrm{~cm}^{-1}$ and $500 \mathrm{~cm}^{-1}$, as well as between $2050 \mathrm{~cm}^{-1}$ and $950 \mathrm{~cm}^{-1}$, for survey and detailed spectra, respectively. We processed the data by a linear baseline subtraction and utilized a Gaussian type fit for three first order Raman bands ( $G$ at $\sim 1590 \mathrm{~cm}^{-1}$, D at $\sim 1350 \mathrm{~cm}^{-1}$, D' at $\left.\sim 1620 \mathrm{~cm}^{-1}\right) ., 49-53$

X-ray photoelectron spectroscopy (XPS).-All samples (pristine, activated, soaked and aged) were pre-treated by sputtering a $30 \mathrm{~nm}$ layer of $\mathrm{Au}$ onto the felt surface to provide an external calibration point (Binding Energy of $\mathrm{Au}_{4 \mathrm{f} 7 / 2}=84.0 \mathrm{eV}$ ). The elemental composition and the chemical state of the elements in the sample surfaces were determined by X-ray Photoelectron Spectroscopy (XPS) measurements (PHI 5800 MultiTechnique ESCA System, Physical Electronics). A surface spot of $0.8 \times 0.8 \mathrm{~mm}^{2}$ was used for analysis. The measurements were done using monochromatized $\mathrm{Al} \mathrm{K} \alpha$ radiation $(250 \mathrm{~W}$, $13 \mathrm{kV}$ ), a detection angle of $45^{\circ}$, and pass energies at the analyzer of 93.9 and $29.35 \mathrm{eV}$ for survey and detail spectra, respectively. A mixed Gaussian-Lorentzian function was used to fit the spectra, while using a Shirley-type background subtraction. The $C(1 \mathrm{~s})$ peak was deconvoluted into six peaks corresponding to the functional groups $\mathrm{C}=\mathrm{C}\left(\mathrm{sp}^{2}, 284.1 \mathrm{eV}\right), \mathrm{C}-\mathrm{H}\left(\mathrm{sp}^{3}, 284.9\right), \mathrm{C}-\mathrm{O}-\mathrm{R}\left(\mathrm{sp}^{3}, 285.96 \mathrm{eV}\right)$, $\mathrm{C}=\mathrm{O}\left(\mathrm{sp}^{2}, 288.2 \mathrm{eV}\right), \mathrm{HO}-\mathrm{C}=\mathrm{O}\left(\mathrm{sp}^{2}, 290.4 \mathrm{eV}\right)$, and $\pi-\pi^{*}$-shakeup $(291.61 \pm 0.8 \mathrm{eV}) .{ }^{8,54,55}$ The $\mathrm{O}(1 \mathrm{~s})$ peak was deconvoluted into two peaks corresponding to the functional groups $\mathrm{C}=\mathrm{O}(531.10 \pm 0.8 \mathrm{eV})$ and $\mathrm{C}-\mathrm{O}(532.70 \pm 0.8 \mathrm{eV})$ and fitted for each pristine sample. The same binding energies were applied for the treated samples.

Electrochemical measurements.-All cyclic voltammetry experiments were carried out with a Biologic SP-300 bi-potentiostat in a three-electrode setup, where the carbon felt $\left(1 \times 1 \mathrm{~cm}^{2}\right)$ was utilized as the working electrode with a compression rate of $25 \%( \pm 5 \%)$ achieved by a titanium mesh current collector $(60$ mesh woven from $0.2 \mathrm{~mm}$ diameter wire, Alfa Aesar) and several $0.3 \mathrm{~mm}$ thick titanium spacers, held together by four M1.6 titanium screws. We utilized a platinum plate as counter electrode, and a reversible hydrogen electrode (HydroFlex, Gaskatel) as reference. The influence of the titanium mesh current collector/sample holder was also investigated and was observed to be negligibly small compared to the current densities of the studied samples (see supporting information, Figure S2). Due to the high permeability of the Ti mesh, we assumed all faces of the felt to be fully exposed to the electrolyte and calculated the geometrical surface area (see Table I). To ensure comparability, the orientation and distances of all three electrodes were kept the same. Photographs of the experimental setup can also be found in the supporting information (Figure S1). Cycling in freshly prepared vanadium (IV) electrolyte took place at a scan rate of $5 \mathrm{mV} / \mathrm{s}$ with potential limits of $0.2 \mathrm{~V}$ and $1.8 \mathrm{~V}$ vs. RHE, respectively. Furthermore, we prepared a $0.5 \mathrm{M} \mathrm{H}_{2} \mathrm{SO}_{4}$ solution by diluting sulfuric acid (Suprapur, Merck) with purified water $(18.2 \mathrm{M} \Omega \cdot \mathrm{cm})$ and cycled the carbon felts in that electrolyte at a scan rate of $50 \mathrm{mV} / \mathrm{s}$ with potential limits of $0.0 \mathrm{~V}$ and $1.0 \mathrm{~V}$ vs. RHE, respectively. 


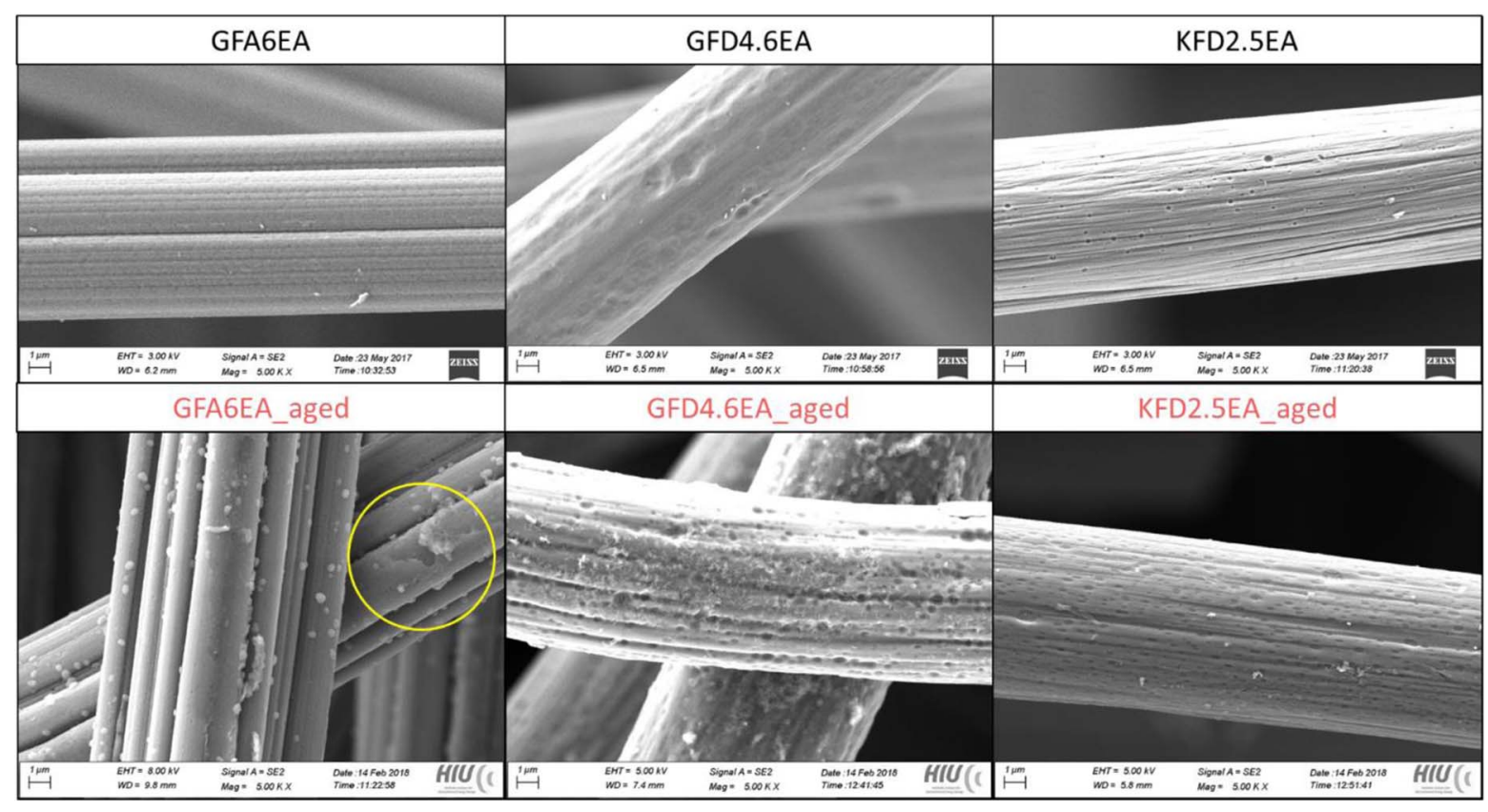

Figure 1. SEM images of the three investigated carbon felts. Top row: pristine. Bottom row: electrochemically aged felts. The yellow circle highlights a flaked off part of the carbon fiber.

\section{Results and Discussion}

SEM.-We utilized scanning electron microscopy to observe the differences between the three felt types and how the treatment methods change the surface morphology. Figure 1 shows the SEM images of the three felts in pristine and electrochemically aged states. In the top row of Figure 1 we can see the differences between the three types of felts. While the Rayon based GFA6EA shows a pronounced grooved and coarse surface, the PAN based GFD4.6EA and KFD2.5EA appear in comparison to be more uniform. The fibers of GFA6EA and KFD2.5EA seem to consist of bundled, thinner fibers with a diameter of about $4 \mu \mathrm{m}$ and $0.5 \mu \mathrm{m}$, respectively, whereas GFD4.6EA fibers consists of one single fiber with some crater-like unevenness with diameters of 0.5 to $2 \mu \mathrm{m}$. Both, thermal treatment and soaking in sulfuric acid didn't alter the surface structure visibly, but we included those SEM images for the sake of completeness in the supporting information (Figure S3). Electrochemical ageing on the other hand has a significant impact on the surface, as shown in the bottom row of Figure 1. A roughening was observed on the surface of the fibers for all three felt types. Furthermore, we noticed a missing part in the structure of GFA6EA, which points toward a flaked off part of the carbon fiber during the ageing (highlighted by the yellow circle).

$\boldsymbol{T G A}-\boldsymbol{M S}$. - Figure 2 shows the results of the TGA-MS measurement for (a) GFA6EA, (b) GFD4.6EA and (c) KFD2.5EA. The top part shows the normalized loss of mass with increase in temperature from ambient to $600^{\circ} \mathrm{C}$. In the bottom part we show the ion currents of water $(\mathrm{m} / \mathrm{z}=18), \mathrm{CO}(\mathrm{m} / \mathrm{z}=28), \mathrm{CO}_{2}(\mathrm{~m} / \mathrm{z}=44)$ and $\mathrm{SO}_{2}(\mathrm{~m} / \mathrm{z}$ $=64$ ), normalized to the initial sample weight to keep the results comparable within one felt type. Whenever there is no signal shown, it is below the detection limit. Here, we utilize the MS date solely for qualitative analysis.

The thermal treatment already shows differences between graphitized and carbonized felts. As expected, it leads to an almost unchanged thermal stability for GFA6EA as well as for GFD4.6EA, while a reduced thermal stability is observed for KFD2.5EA. For KFD2.5EA, we observe a step in TGA of about $10 \%$ until about $150^{\circ} \mathrm{C}$, which can be connected to $\mathrm{CO}_{2}$ peak combined with a high $\mathrm{CO}$ output. Furthermore, the ion current of water was increased by thermal treatment for all felts, which indicates a higher water content and correlates to the wettability, since the activated felts tend to sink in water (hydrophilic) in general, while pristine felts float on top of it (hydrophobic). The increasing water output above $100^{\circ} \mathrm{C}$ can be traced back to the oxidation of hydrogenated carbons since this appears with an increasing $\mathrm{CO}_{2}$ signal. The graphitized felts not only show an overall higher water ion current after thermal treatment, but it is also two orders of magnitude higher than the ion current of the carbonized felt.

Soaking in sulfuric acid for 15 days was found to have a higher impact on the thermal stability of all three felts than electrochemical ageing for 5 days at $1.2 \mathrm{~V}$ in a $\mathrm{V}(\mathrm{V})$-electrolyte. For graphitized felts, both treatment methods led to a reduced ion current of water compared to the activated felt, while electrochemical ageing increases the ion current of $\mathrm{CO}$ and $\mathrm{CO}_{2}$ strongly above $150^{\circ} \mathrm{C}$. This is also seen in the mass loss and indicates a removal of oxygen containing surface groups. For GFD4.6EA, there is a strong mass loss of about $10 \%$ until $200^{\circ} \mathrm{C}$, which correlates to a high $\mathrm{SO}_{2}$ ion current due to trapped residues of sulfuric acid. In contrast, for the carbonized felt (KFD2.5EA) the mass loss shows two pronounced steps: the first step at $150^{\circ} \mathrm{C}$ can be correlated to a strong $\mathrm{CO}_{2}$ output, and the second step at $290^{\circ} \mathrm{C}$ occurs due to a high water and $\mathrm{SO}_{2}$ output, which is strongly visible in the soaked sample. The increased $\mathrm{CO}_{2}$ output can be explained by the degradation of functional surface groups of the carbon felt, while $\mathrm{SO}_{2}$ indicates residual sulfuric acid. In general, we observed that the prolonged period of the soaking treatment had a stronger influence on the thermal stability than the application of potential and vanadium containing electrolyte.

Raman.-We applied Raman spectroscopy to investigate the changes in graphitization induced by the treatment methods. We utilized the intensity of the following first order Raman bands: The ideal graphitic lattice ( $\mathrm{G}$ band at $\sim 1590 \mathrm{~cm}^{-1}$ ), the disordered graphitic lattice on the edges ( $\mathrm{D}$ band at $\sim 1350 \mathrm{~cm}^{-1}$ ), and the disordered graphitic lattice on the surface layer (D' band at $\sim 1620 \mathrm{~cm}^{-1}$ ). ${ }^{8,53}$ The intensities of the $\mathrm{D}$ and $\mathrm{G}$ bands were utilized to calculate the $I_{D} / I_{G}$ ratio. ${ }^{56,57}$ An increase in the ratio corresponds to more disorders and defects, while a decrease means more graphitic domains with reduced disorders and defects, so it can be interpreted as a degree of graphitization. ${ }^{58}$ Figure 3 shows the envelope of the Raman spectra of all investigated felts before and after the treatments, after fitting the three bands. 

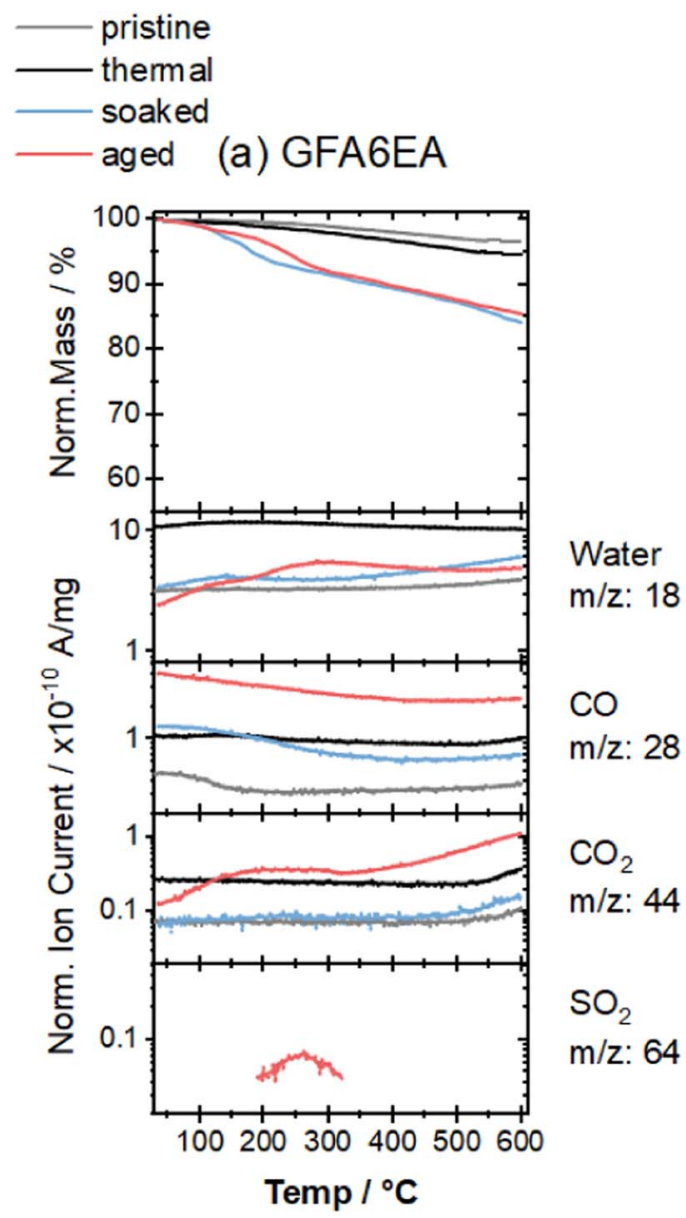

(b) GFD4.6EA

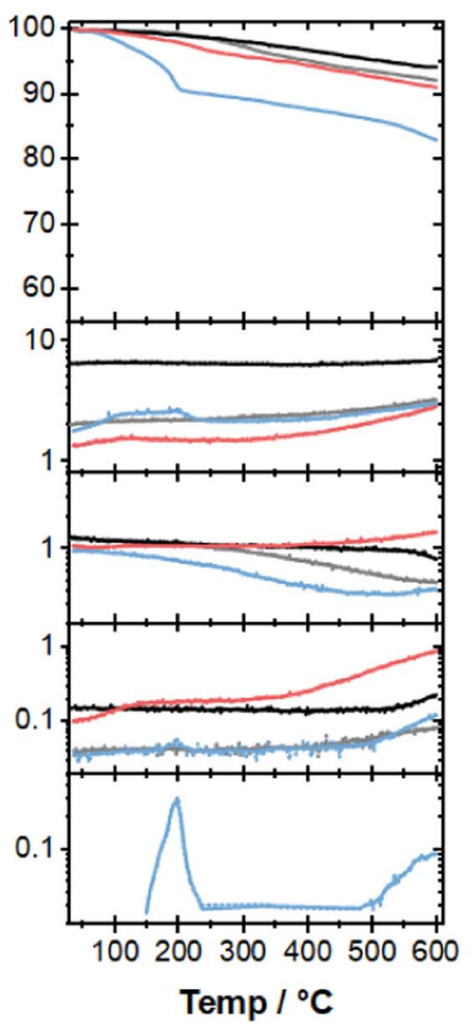

(c) KFD2.5EA

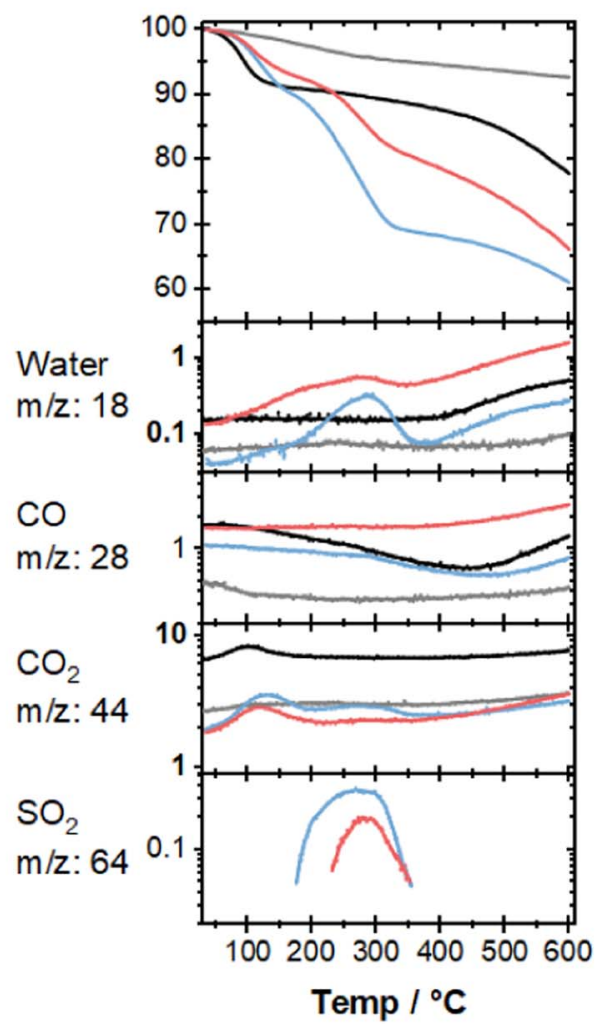

Figure 2. TGA-MS of (a) GFA6EA, (b) GFD4.6EA and (c) KFD2.5EA. Please note, that the scales are different for Water and CO 2 at (c).

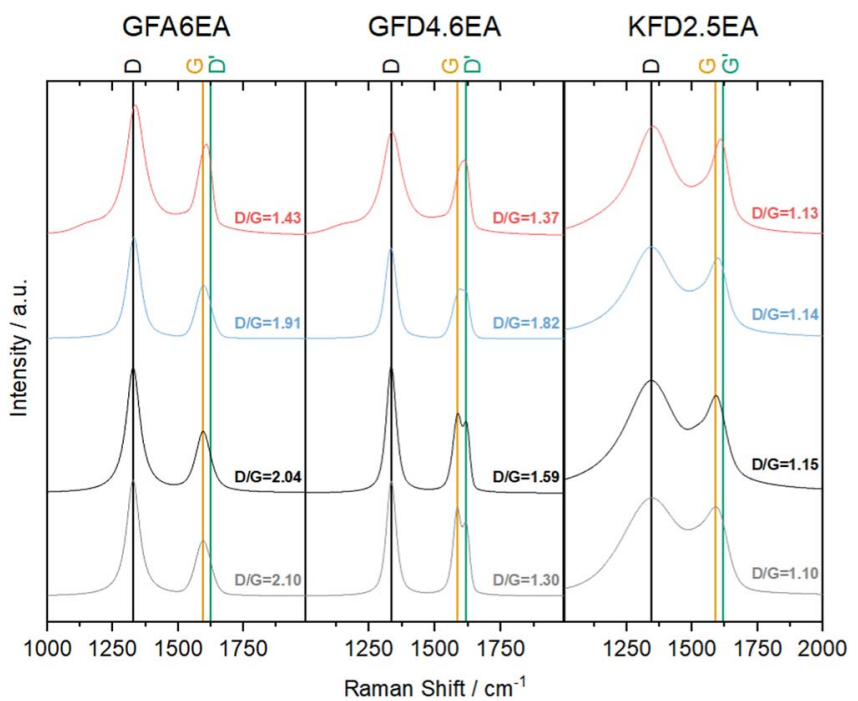

Figure 3. Effects of the treatment methods on Raman spectra of all investigated felt types.

For the pristine felts, the Rayon based GFA6EA has a much higher $I_{D} / I_{G}$ ratio (2.10), compared to the PAN based GFD4.6EA and KFD2.5EA with a similar ratio of 1.30 and 1.10, respectively. This suggests a higher graphitization of the PAN based felt types and is in good agreement with the increased electrical conductivity observed in the literature. ${ }^{37}$
In general, thermal treatment only slightly changes the $I_{D} / I_{G}$ ratio for all felt types. We observe a slight decrease for the Rayon based GFA6EA from 2.10 to 2.04 and a slight increase for the PAN based GFD4.6EA (1.30 to 1.59) and KFD2.5EA (1.10 to 1.15), which can be caused by the oxidation of the surface and thus introducing more defects. The D' band is well pronounced only at pristine and activated GFD4.6EA which indicates defects in the surface layer of the graphitic lattice. Both, soaking in sulfuric acid, and electrochemical ageing don't affect the $I_{D} / I_{G}$ ratio for KFD2.5EA. This can be linked to the carbonized structure of this felt, which is also indicated by the broadened bands in general. Soaking reduces the $I_{D} / I_{G}$ ratio for GFA6EA slightly (-7\%) and increases for GFD4.6EA $(+14 \%)$. This indicates a further increase in graphitic domains for GFA6EA and more defects and disorders for GFD4.6EA, which is also in good agreement with the TGA-MS data, where an increase of defects can lead to a decreased thermal stability. The electrochemical ageing decreases the $I_{D} / I_{G}$ ratio of GFA6EA $(-30 \%)$ more than the ratio of GFD4.6EA (-13\%), which points to larger graphitic domains and possibly fewer functional groups.

XPS.-We applied XPS to investigate the effects of the treatment methods on the surface functional groups. Table II shows the assignment of the surface species to the deconvoluted peak at the corresponding binding energy and Figure 4 shows how it was applied for the XP spectra of GFA6EA.

To provide comparable surface related values, we first calculated several ratios and plotted them in the following section in Figures 5a, $5 \mathrm{~b}$ and $5 \mathrm{c}$ for GFA6EA, GFD4.6EA, and KFD2.5EA, respectively. The $\mathrm{O} / \mathrm{C}$ ratio was obtained from the atomic composition, which was calculated by the means of the Scofield atomic sensitivity factors and 


Table II. Deconvoluted peaks and their assigned species.
\begin{tabular}{ll} 
Binding Energy/eV & Assigned species \\
\hline 284.1 & $\mathrm{C}=\mathrm{C}\left(\mathrm{sp}^{2}\right)$ \\
284.9 & $\mathrm{C}-\mathrm{H}\left(\mathrm{sp}^{3}\right)$ \\
285.96 & $\mathrm{C}-\mathrm{O}-\mathrm{R}\left(\mathrm{sp}^{3}\right)$ \\
288.2 & $\mathrm{C}=\mathrm{O}\left(\mathrm{sp}^{2}\right)$ \\
290.4 & $\mathrm{HO}-\mathrm{C}=\mathrm{O}\left(\mathrm{sp}^{2}\right)$ \\
$291.61( \pm 0.8)$ & $\pi-\pi^{*}-$ shakeup \\
$531.10( \pm 0.8)$ & $\mathrm{C}=\mathrm{O}$ \\
$532.70( \pm 0.8)$ & $\mathrm{C}-\mathrm{O}$ \\
\end{tabular}

the intensity of each element peak in the XP spectrum. The ratio of $\mathrm{sp}^{2} / \mathrm{sp}^{3}$ was calculated by the sum of $\mathrm{sp}^{2}$ peak areas A over sum of $\mathrm{sp}^{3}$ peak areas A of deconvoluted C(1s) peak, as shown in Equation 1:

$$
\frac{s p^{2}}{s p^{3}}=\frac{A_{C=C}+A_{C=O}+A_{C O O H}}{A_{C-H}+A_{C-O R}}
$$

The peak areas A of deconvoluted $\mathrm{O}(1 \mathrm{~s})$ peak were utilized to calculate the $\mathrm{C}=\mathrm{O} / \mathrm{C}-\mathrm{O}$ ratio.

In the following section, Figure 6, Figure 7, and Figure 8 show the contents of carbon and oxygen species of the deconvoluted $\mathrm{C}(1 \mathrm{~s})$ and $\mathrm{O}(1 \mathrm{~s})$ peaks for each treatment method applied on GFA6EA, GFD4.6EA, and KFD2.5EA, respectively. For each treated felt we show two connected stacked-bars, where each left bar represents the relative content of the carbon species and each right bar represents the oxygen species with each value included in the bar. The carbon species are $\mathrm{C}=\mathrm{C}$ (black), $\mathrm{C}=\mathrm{O}$ (teal), $\mathrm{COOH}$ (yellow), $\mathrm{C}-\mathrm{H}$ (orange), $\mathrm{C}$-OR (light blue) and $\pi-\pi^{*}$-shakeup (dark blue), the oxygen species (a)

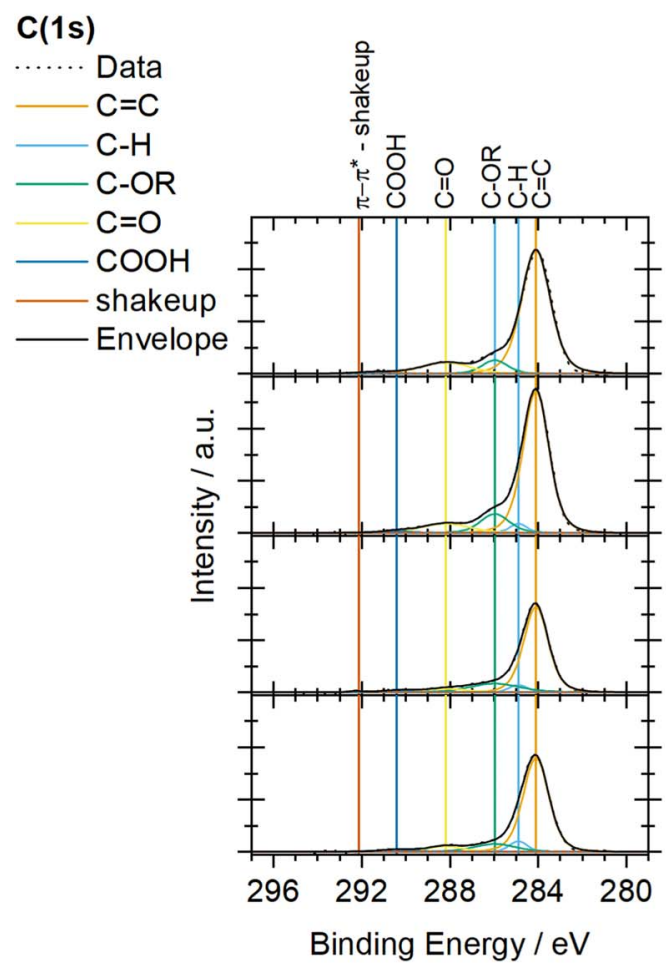

(b)

\section{$\mathrm{O}(1 \mathrm{~s})$}

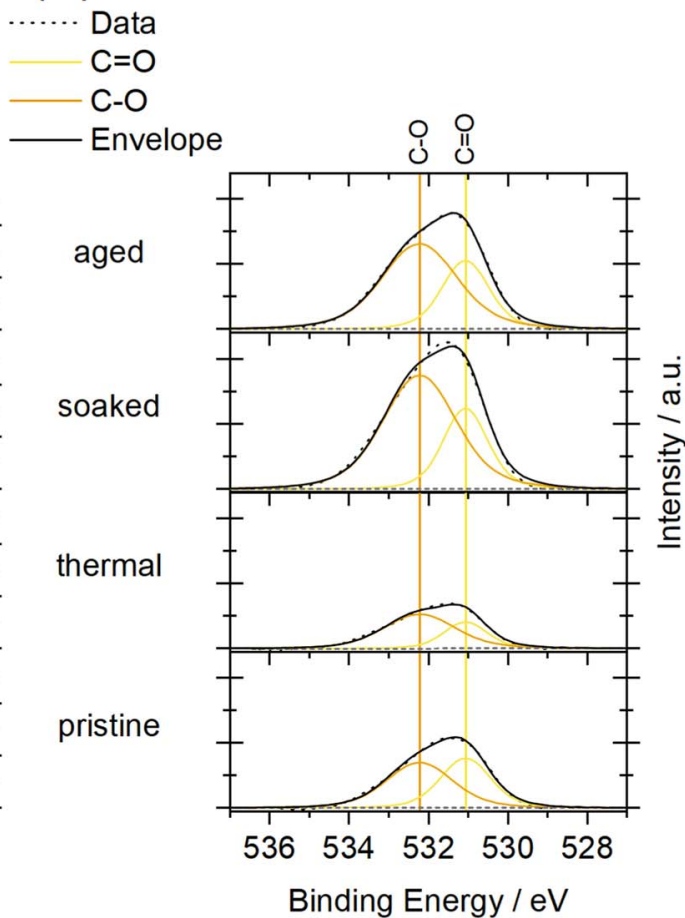

Figure 4. (a) $\mathrm{C}(1 \mathrm{~s})$ and (b) $\mathrm{O}(1 \mathrm{~s}) \mathrm{XP}$ spectra of GFA6EA for all treatment methods with the corresponding deconvoluted peaks.

(a) GFA6EA

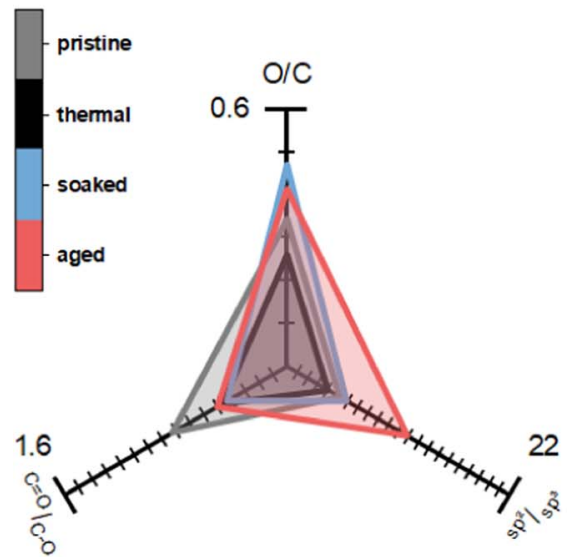

(b) GFD4.6EA

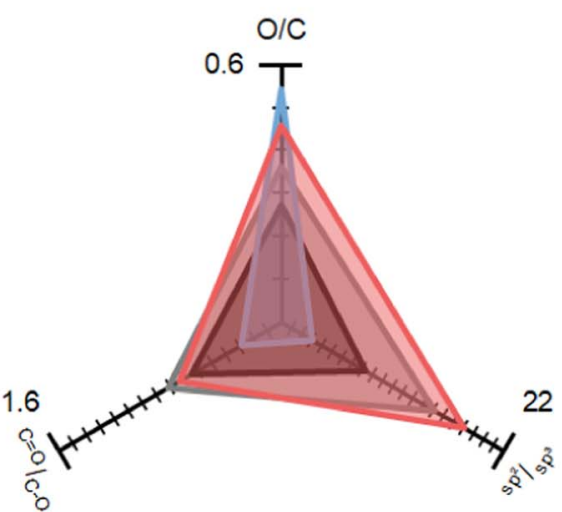

(c) KFD2.5EA

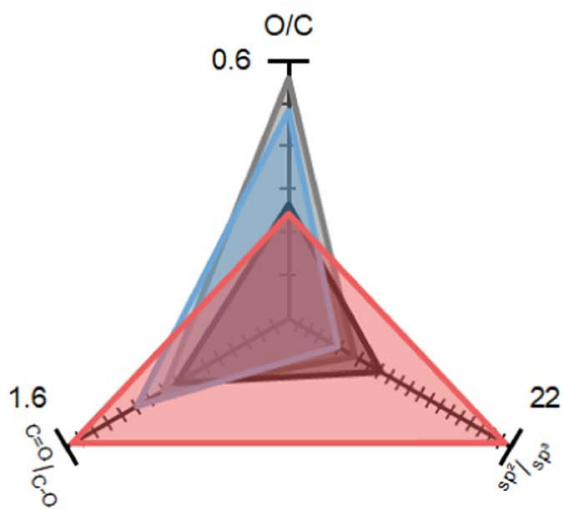

Figure 5. Effects of the treatment methods on $\mathrm{O} / \mathrm{C}, \mathrm{sp}^{2} / \mathrm{sp}^{3}$ and $\mathrm{C}=\mathrm{O} / \mathrm{C}-\mathrm{O}$ ratios for (a) GFA6EA, (b) GFD4.6EA and (c) KFD2.5EA. 


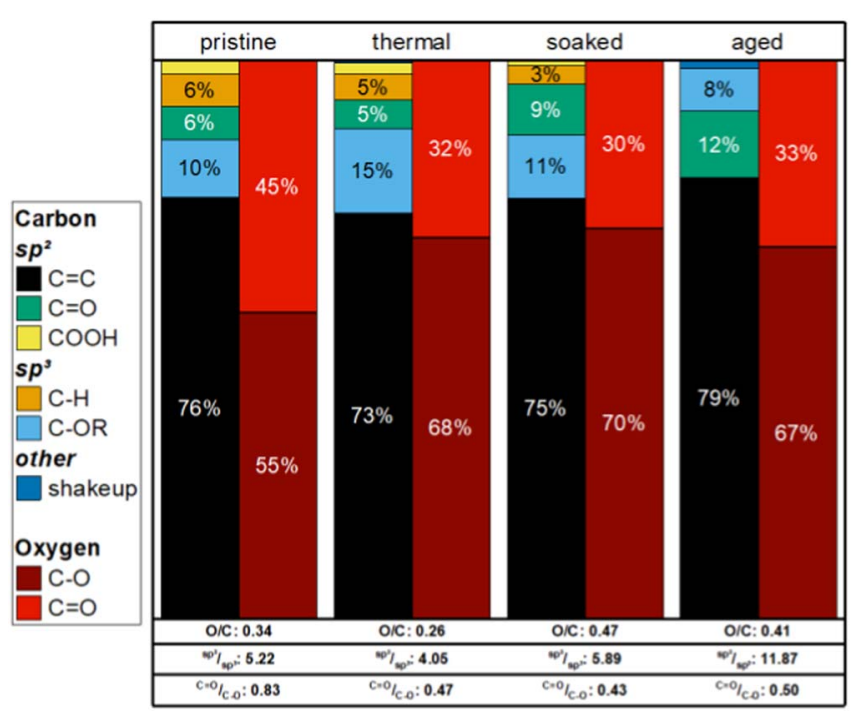

Figure 6. Effects of the treatment methods on the relative contents of each carbon and oxygen for GFA6EA.

are $\mathrm{C}-\mathrm{O}$ (dark red) and $\mathrm{C}=\mathrm{O}$ (red). In the bottom of Figure 6 we show a table of the ratios calculated by means of the deconvoluted $\mathrm{C}(1 \mathrm{~s})$ and $\mathrm{O}(1 \mathrm{~s})$ peaks $\left(\mathrm{O} / \mathrm{C}, \mathrm{sp}^{2} / \mathrm{sp}^{3}, \mathrm{C}=\mathrm{O} / \mathrm{C}-\mathrm{O}\right.$, plotted in Figure 5$)$ of each treated felt.

GFA6EA.-For the Rayon based, graphitized carbon felt (GFA6EA) we observe, that the thermal treatment leads to a reduced $\mathrm{O} / \mathrm{C}$ ratio, which has been reported in the literature to be caused by the removal of volatile $\mathrm{C}-\mathrm{O}$ contaminants. ${ }^{8,37}$ Additionally it is shown in Figure 5a, that both, the $\mathrm{sp}^{2} / \mathrm{sp}^{3}$ and $\mathrm{C}=\mathrm{O} / \mathrm{C}-\mathrm{O}$ ratios get reduced by $20 \%$ and $40 \%$, respectively, which is mainly the result of the increasing C-OR content, as it is shown in Figure 6. Consequently, more oxygen is now bonded to $\mathrm{sp}^{3}$-carbon.

Soaking and electrochemical ageing increase the overall oxygen content by $10 \%$ and $8 \%$, respectively, referred to the activated sample. As shown in Figure 5a and Figure 6, there is only a small change in the $\mathrm{C}=\mathrm{O} / \mathrm{C}-\mathrm{O}$ ratio, which leads back to a reduced $\mathrm{C}-\mathrm{OR}$ content $(15 \%$ to $11 \%$ and $8 \%$, respectively) and increased $\mathrm{C}=\mathrm{O}$ content $(5 \%$ to $9 \%$ and $12 \%$, respectively). This means that the oxygen containing carbon

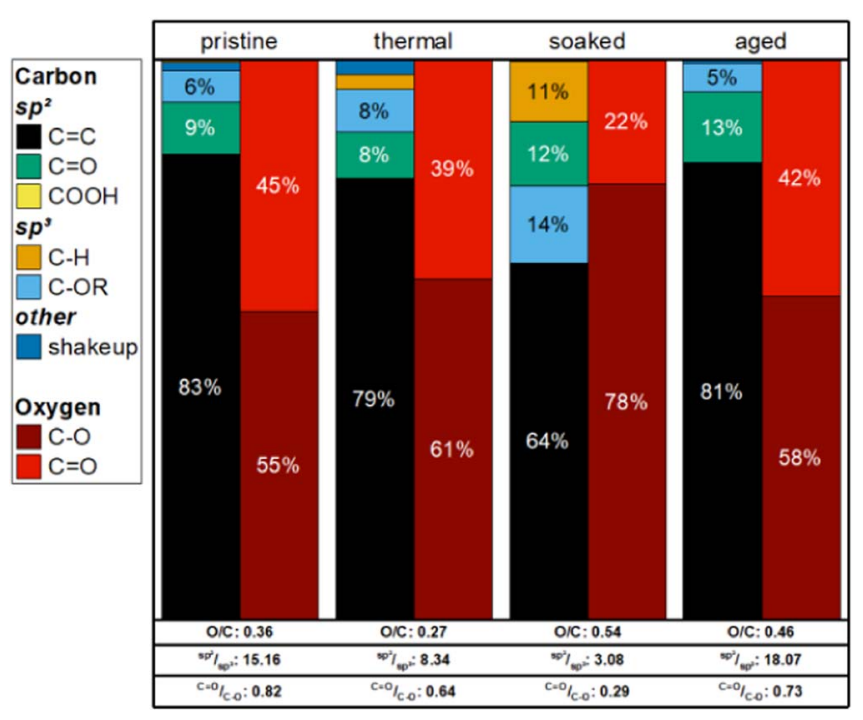

Figure 7. Effects of the treatment methods on the relative contents of each carbon and oxygen for GFD4.6EA.

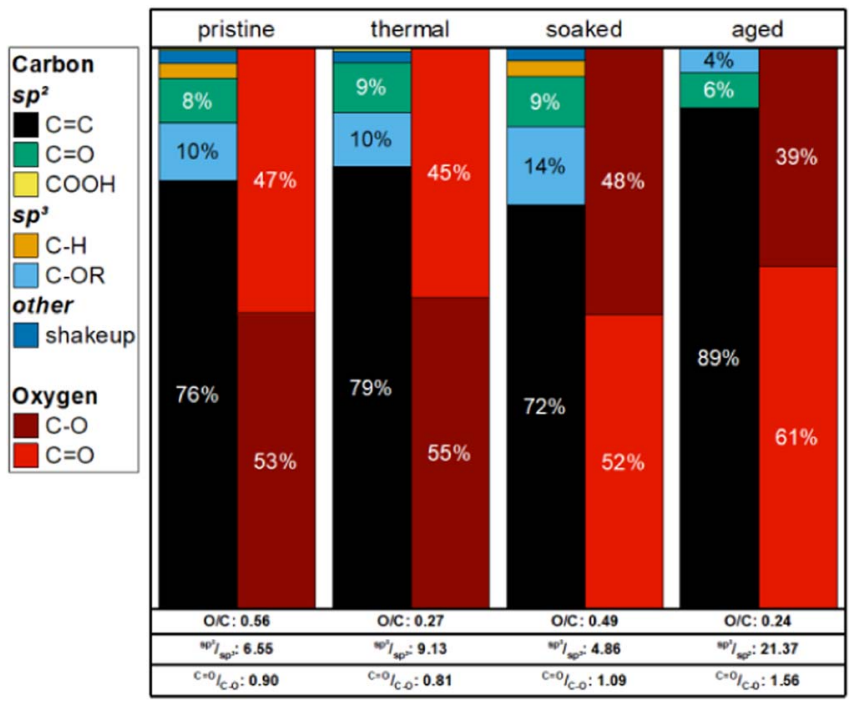

Figure 8. Effects of the treatment methods on the relative contents of each carbon and oxygen for KFD2.5EA.

species were oxidized to $\mathrm{C}=\mathrm{O}$ - especially by electrochemical ageing. The increasing signal of $\pi-\pi^{*}$-shakeup backs the decreasing $I_{D} / I_{G}$ ratio of Raman as well as the excessive increase in the $\mathrm{sp}^{2} / \mathrm{sp}^{3}$ ratio, which imply a higher graphitic content. Furthermore, the changes of the species content agree with Raman: the thermal treatment reduces the number of defects (contaminants), soaking and electrochemical ageing lead to a higher graphitic content due to more $\mathrm{sp}^{2}$-carbon.

GFD4.6EA.-The PAN based, graphitized GFD4.6EA shows a similar behavior like GFA6EA during the thermal treatment. As shown in Figure $5 b$, the total oxygen content gets reduced by $25 \%$ (Nibel et al. ${ }^{8}$ observed $33 \%$ ), as well as the $\mathrm{C}=\mathrm{O} / \mathrm{C}-\mathrm{O}$ ratio by $22 \%$ and $\mathrm{sp}^{2} / \mathrm{sp}^{3}$ ratio by $45 \%$. The content of C-OR doesn't increase as much as for GFA6EA, since the $\mathrm{sp}^{2}$ content is much higher initially (see Figure 7). This is also in agreement with the Raman spectra: $I_{D} / I_{G}$ increases from 1.30 to 1.59 , which means that the degree of graphitization becomes lower.

Soaking affects this PAN based felt much more than electrochemical ageing. While the total oxygen content increases for both, soaking leads to more defects (cf. Raman) and a strong increase in $\mathrm{sp}^{3}$ hybritized carbon in the form of $\mathrm{C}-\mathrm{H}$ and $\mathrm{C}-\mathrm{OR}$ and single-bonded oxygen, as shown in Figure 7. This also leads to a decrease of the $\mathrm{C}=\mathrm{O} / \mathrm{C}-\mathrm{O}$ ratio by $55 \%$, mainly due to the increase of C-O. Furthermore, the overall oxygen content relatively increases from close to $20 \%$ to slightly above $30 \%$, while the overall carbon content gets reduced by $12 \%$. This results in an increase of the $\mathrm{O} / \mathrm{C}$ ratio from 0.27 to 0.54 . Due to more defects, even more edges are introduced, which lead to noticeably higher $\mathrm{C}-\mathrm{H}$ and $\mathrm{C}-\mathrm{OR}$ contents. Electrochemical ageing on the other hand leads to more oxidization of the surface to double-bonded oxygen: The C-OR content gets reduced along with a significant increase of the $\mathrm{sp}^{2} / \mathrm{sp}^{3}$ by $116 \%$. Raman showed a decrease of the $I_{D} / I_{G}$ ratio by $14 \%$, which again means fewer defects and more graphitized domains.

KFD2.5EA.-Carbonized felts like KFD2.5EA, generally have a higher O content (around 30\%) compared to graphitized ones (around $20 \%)$ and the oxygen is almost equally single- and double-bonded $(\mathrm{C}=\mathrm{O} / \mathrm{C}-\mathrm{O}=0.9)$, as plotted in Figure $5 \mathrm{c}$. The thermal treatment reduces the oxygen content strongly to below $20 \%$, while it increases the $\mathrm{sp}^{2} / \mathrm{sp}^{3}$ ratio. Since $\mathrm{C}=\mathrm{O} / \mathrm{C}-\mathrm{O}$ only slightly decreases, and the Raman measurements show a slightly increasing $I_{D} / I_{G}$ ratio (more defects), this means an increase in $\mathrm{C}=\mathrm{O}$ and $\mathrm{C}=\mathrm{C}$ contents by $12 \%$ and $4 \%$, respectively. 


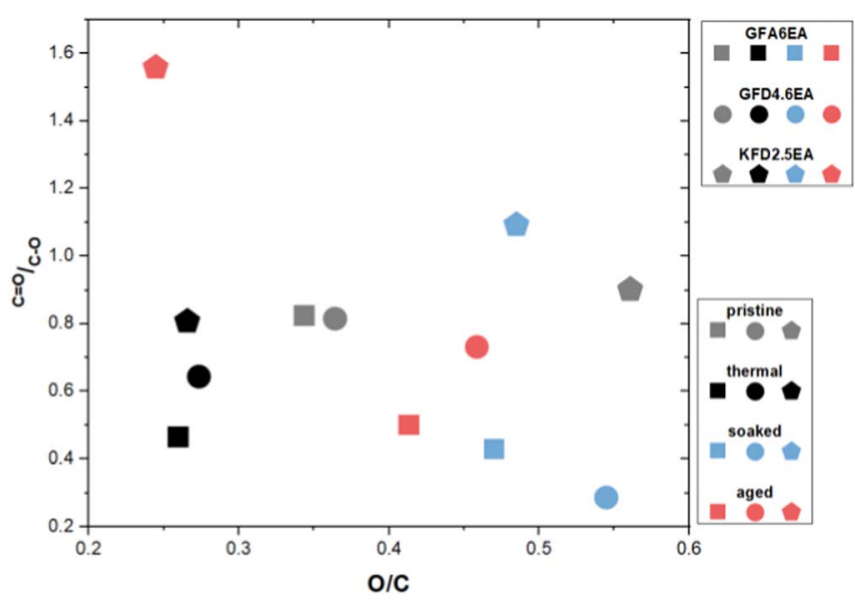

Figure 9. Correlation of $\mathrm{C}=\mathrm{O} / \mathrm{C}-\mathrm{O}$ and $\mathrm{O} / \mathrm{C}$ ratios during the treatment procedures for all investigated carbon felts.

The oxygen content is further increased by soaking in sulfuric acid and even increases $\mathrm{C}=\mathrm{O} / \mathrm{C}-\mathrm{O}$ to above 1 , which reflects in the strongly decreasing $\mathrm{sp}^{2} / \mathrm{sp}^{3}$-ratio: $\mathrm{C}=\mathrm{C}$ content decreases, while $\mathrm{C}$ $\mathrm{OR}$ and $\mathrm{C}=\mathrm{O}$ contents increase (cf. Figure 8 ). This reflects in a very high $\mathrm{CO}_{2}$ output in TGA-MS. Additionally, a relatively high signal of $\pi-\pi^{*}$-shakeup points toward a pronounced aromaticity in the carbon layers. ${ }^{59}$ In contrast, electrochemical ageing reduces the oxygen content further with a strong increase in the $\mathrm{sp}^{2} / \mathrm{sp}^{3}$ and $\mathrm{C}=\mathrm{O} / \mathrm{C}$ $\mathrm{O}$ ratios. There is a much-reduced content of C-O-R and oxygen is mainly double-bonded. The main contribution to the high $\mathrm{sp}^{2} / \mathrm{sp}^{3}$ ratio are $\mathrm{C}=\mathrm{C}$ bonds. As mentioned above, Raman doesn't change significantly for both ageing procedures.

To show general trends in the XPS measurements, and to outline commonalities and differences we plotted the $\mathrm{O} / \mathrm{C}$ ratios versus the $\mathrm{C}=\mathrm{O} / \mathrm{C}-\mathrm{O}$ ratios of all felts in Figure 9. The felts GFA6EA, GFD4.6EA and KFD2.5EA, are represented by squares, circles and pentagons, respectively, and the applied treatment method is indicated by the colors gray, black, blue and red (pristine, activated, soaked and aged).

For all felts in general, the thermal treatment decreases the O/C ratios, as we show in Figure 9 looking at the path from gray symbols to black symbols. Going from the black symbols further to blue or red, which represents soaking in sulfuric acid and electrochemical ageing, respectively, we can see an increase of the O/C ratio for the graphitized felts (square and circle), while it gets slightly reduced for the carbonized felt (pentagon).

Cyclic voltammetry.-To further investigate the effects of the treatment methods on electrochemical performance of the felts, we utilized cyclic voltammetry in a $\mathrm{V}(\mathrm{IV})$ electrolyte with a scan rate $\nu=10 \mathrm{mV} / \mathrm{s}$ and calculated the peak separation $\Delta \mathrm{E}$ and the baseline subtracted peak current ratio $I_{p c} / I_{p a}$ for the $V(I V) / V(V)$ redox couple for each felt before and after each treatment. The theoretical peak separation for an electrochemically reversible process with a fast electron transfer is ca. $57 \mathrm{mV}$ and the peak current ratio equals 1 , since the same amount of electrons is transferred during oxidation and reduction, resulting in the same current for a given scan rate; the closer the measured values are to the theoretical values, the higher the reversibility. ${ }^{19,60-62}$ The compression rate induced by the titanium mesh current collector is $65 \pm 5 \%$ and leads to a geometric area A of $2.27 \mathrm{~cm}^{2}$ for GFA6EA and GFD4.6EA, and $2.36 \mathrm{~cm}^{2}$ for KFD2.5EA. Figure 10 shows the comparison of the cyclic voltammograms in the vanadium electrolyte of all treatments for (a) GFA6EA, (b) GFD4.6EA and (c) KFD2.5EA. Additionally, we performed cyclic voltammetry in $0.5 \mathrm{M}$ sulfuric acid to qualitatively compare the effects of the treatment methods on the double layer capacity and the occurrence of the quinone/hydroquinone redox couple, which indicates the reversible oxidation and reduction of oxygen containing species on the carbon surface. ${ }^{63-65}$ The resulting cyclic voltammograms in sulfuric acid are shown in Figure 12 for (a) GFA6EA, (b) GFD4.6EA and (c) KFD2.5EA.

GFA6EA.-In Figure 11, the peak separation $\triangle \mathrm{E}$ and the peak current ratio $\mathrm{I}_{\mathrm{pc}} / \mathrm{I}_{\mathrm{pa}}$ for non-activated, activated, soaked and aged GFA6EA are shown as bar and scatter plot, respectively. Thermal treatment results in an increasing peak separation, which can imply lower conductivity. This correlates to the decreasing $\mathrm{sp}^{2} / \mathrm{sp}^{3}$ ratio and the increased ratio of oxygen bonded to $\mathrm{sp}^{3}$-carbon. Furthermore, with thermal treatment the peak current ratio approaches to unity, which implies a better reversibility due to the facilitated formation of $-\mathrm{C}-\mathrm{O}-\mathrm{V}$ bonds by the means of a high C-O content. ${ }^{34}$

Soaking in sulfuric acid decreases the peak separation again while further approaching unity in peak current ratio, which means higher reversibility while maintaining a high conductivity. As XPS shows an (a) GFA6EA

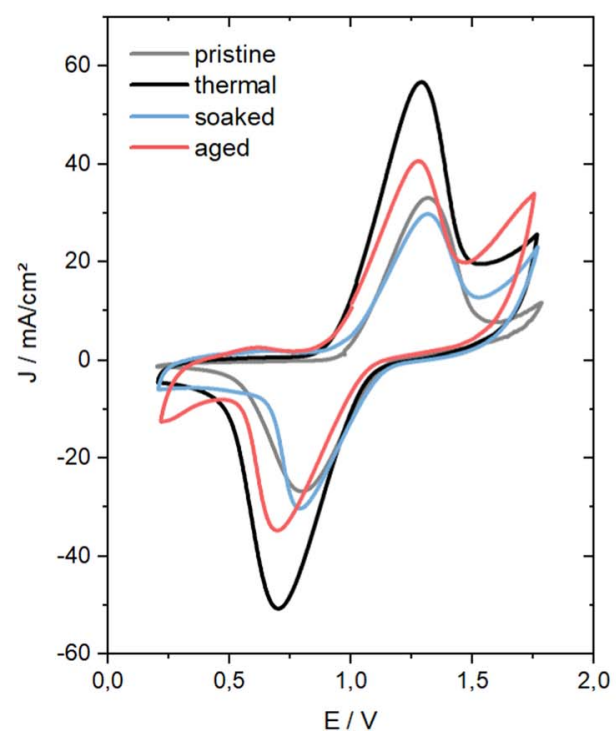

(b) GFD4.6EA

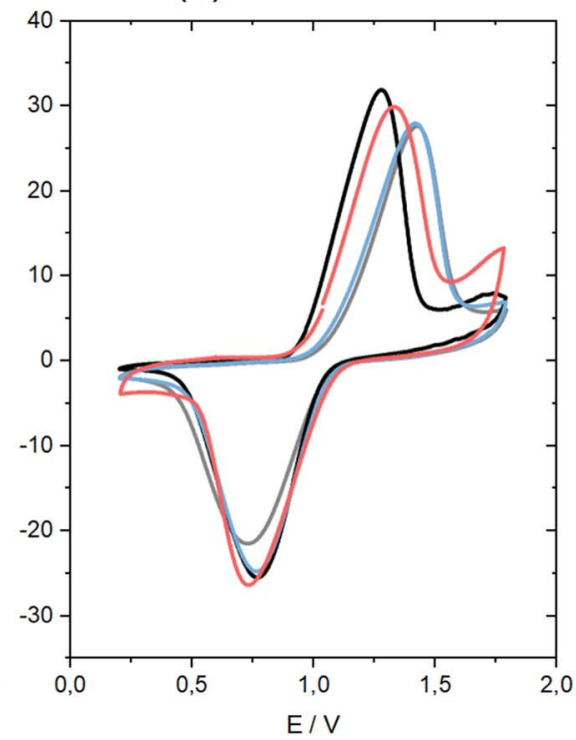

(c) KFD2.5EA

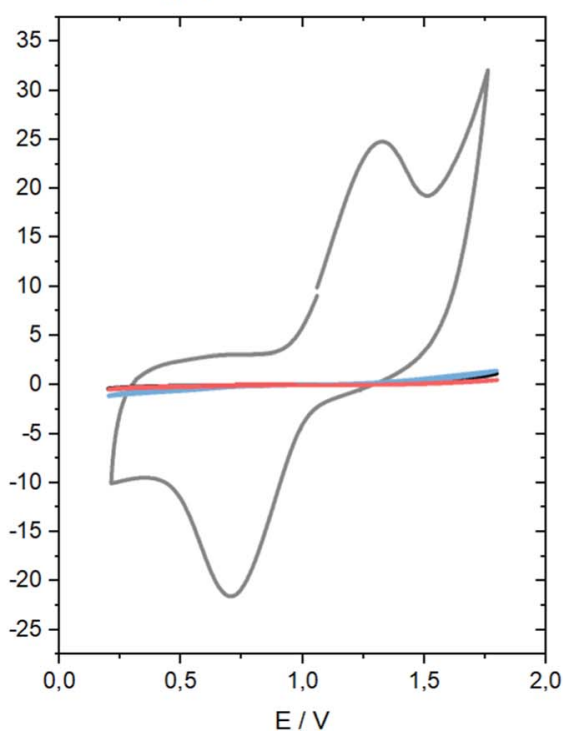

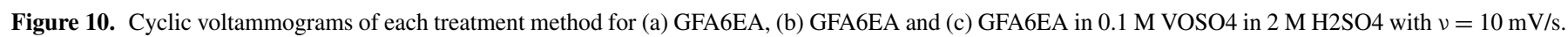


(a) GFA6EA

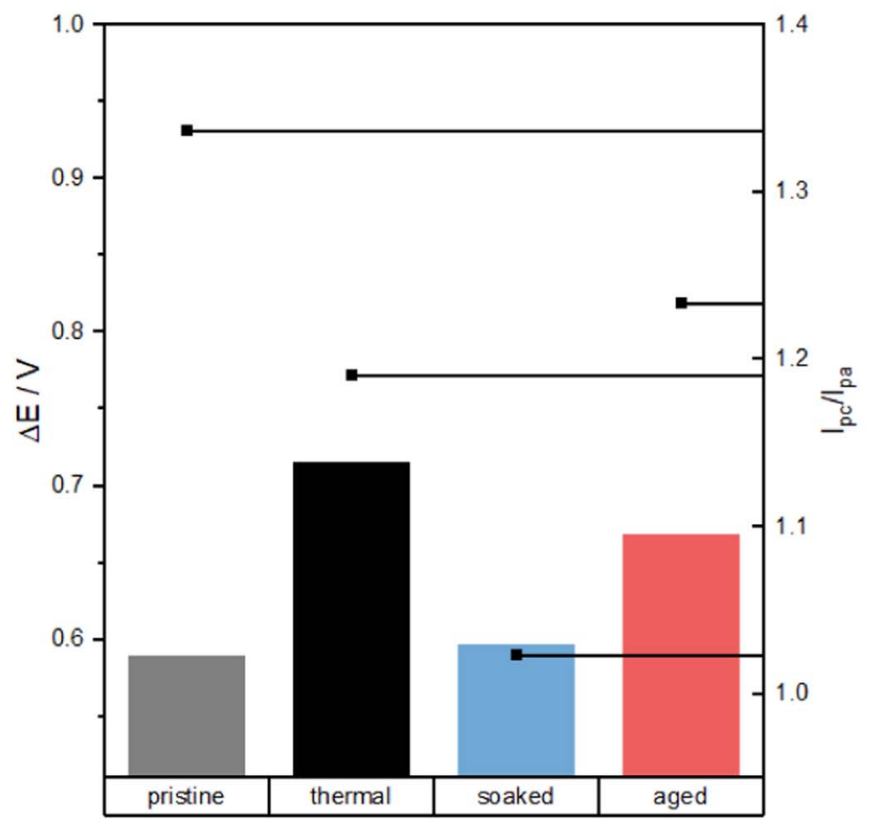

(b) GFD4.6EA

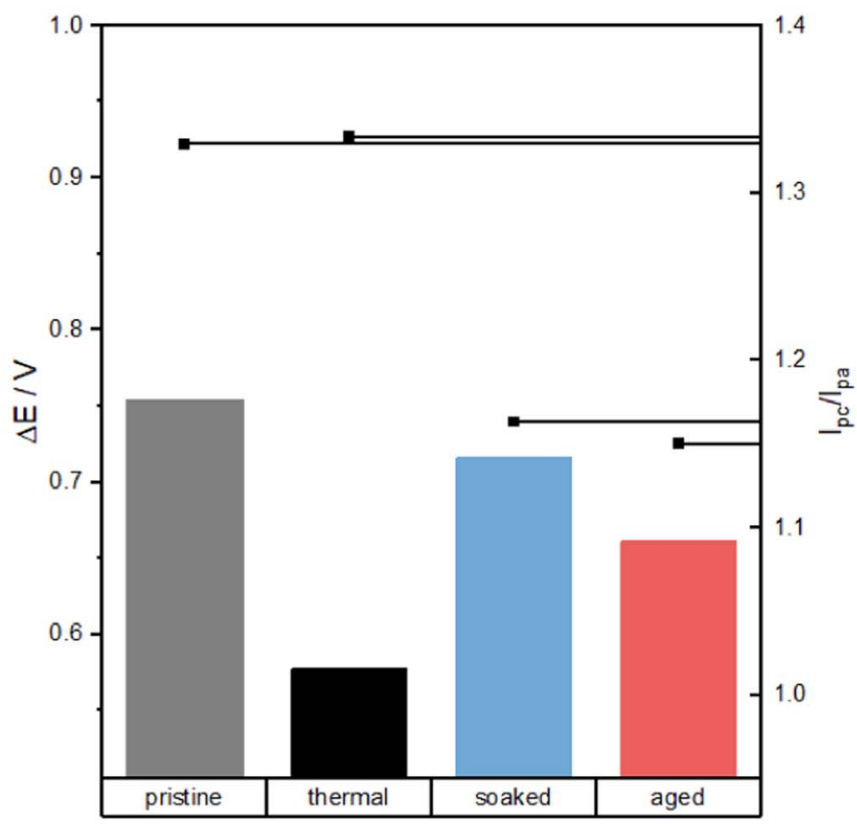

Figure 11. The effect of the treatment methods on $\triangle \mathrm{E}$ and Ipc/Ipa for (a) GFA6EA and (b) GFD4.6EA.

increased oxygen content and the even further decreased $\mathrm{C}=\mathrm{O} / \mathrm{C}-\mathrm{O}$ ratio, this could mean that this treatment "activated" the sample even further. With the high total oxygen content in mind, TGA-MS shows a reduced thermal stability along with a high $\mathrm{CO}$ output until $200^{\circ} \mathrm{C}$ (see Figure $2 \mathrm{a}$, which points to decomposition of aldehydes/ketones. ${ }^{64,66}$

The electrochemical ageing on the other hand reduces the peak separation due to the increased conductivity originating in the high $\mathrm{C}=\mathrm{C}$ content. The current peak ratio increases, which indicates a poor reversibility due to a reduced $\mathrm{C}-\mathrm{O}-\mathrm{R}$ content. Furthermore, side reactions like carbon corrosion occur, as it is indicated by the increased current density for potentials above around 1.5 V in Figure 10a. This explains the decreased anodic current: possible reaction sites are not part of the material anymore and are missing during the reduction reaction in the backward scan. Furthermore, a quinone/hydroquinone redox couple at around $0.5 \mathrm{~V}$ vs. RHE appears, which is highly dependant on the surface structure. XPS shows a very high $\mathrm{C}=\mathrm{O}$ content (which is part of a quinone) for the electrochemical ageing, as well as a very high $\mathrm{sp}^{2} / \mathrm{sp}^{3}$ ratio, compared to the other treatment methods. In the cyclic voltammograms in pure sulfuric acid (Figure 12a) the electrochemically treated sample has by far the highest current densities and shows the most pronounced quinone/hydroquinone peaks as well. Here, these peaks are also visible for the other treatment methods. The current densities of the electrochemically aged sample in sulfuric acid are shown with a factor of 0.5 to increase (a) GFA6EA

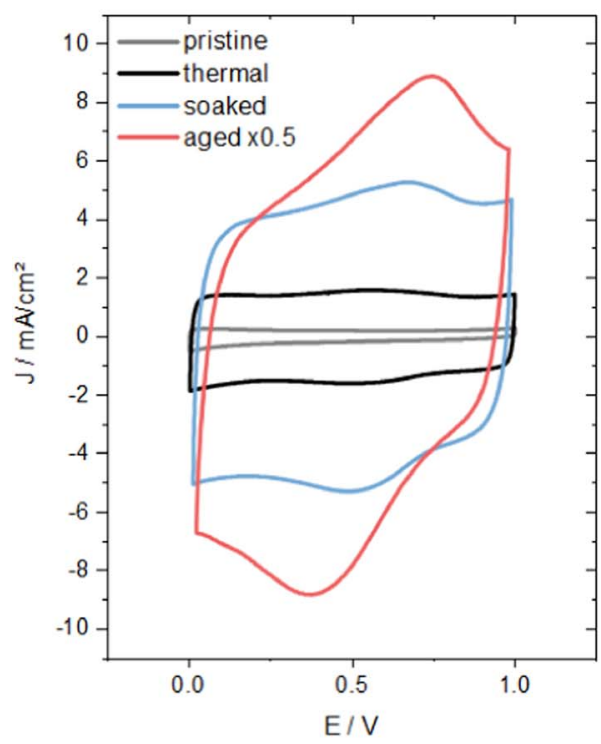

(b) GFD4.6EA

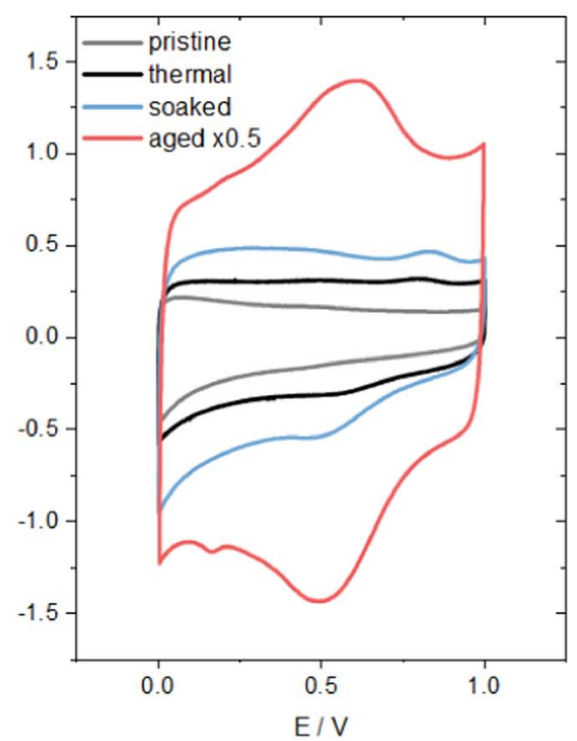

(c) KFD2.5EA

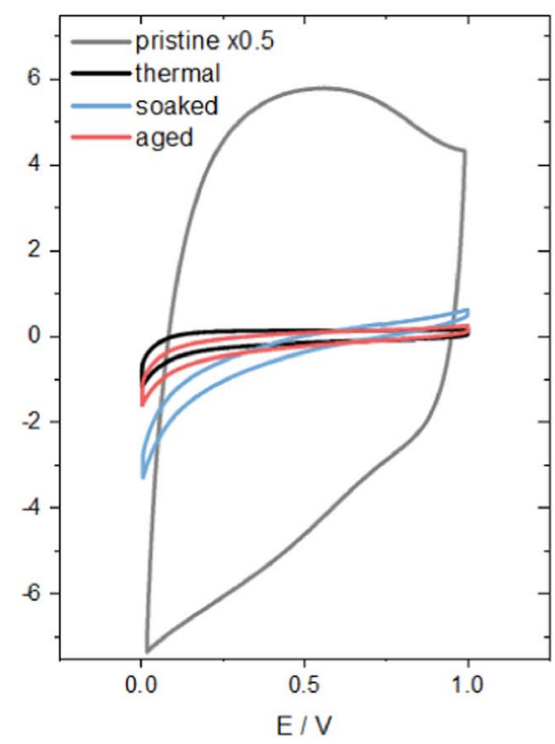

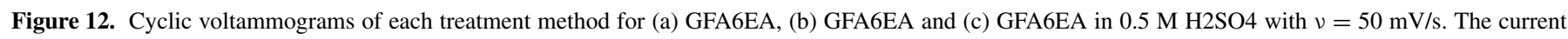
densities were reduced by a factor of 0.5 for the aged felt (red) in (a) and (b) and the non-activated felt (gray) in (c) to increase visibility. 
visibility and comparability within the plot. Comparing the current densities of the cyclic voltammograms in the vanadium (IV) electrolyte (Figure 10a) with the ones in pure sulfuric acid, it was observed that they were several times higher in the vanadium (IV) electrolyte. The current densities of e.g. the hydroquinone oxidation is around $1 \mathrm{~mA} / \mathrm{cm}^{2}$ for the thermally treated GFA6EA, whereas the current densities of the oxidation of vanadium (IV) to vanadium (V) for the same sample almost reaches $60 \mathrm{~mA} / \mathrm{cm}^{2}$. This means it is almost impossible to see the quinone/hydroquinone redox couple with the applied scaling.

As shown in Figure 12a, the thermal treatment of the carbon felt leads to an increased double layer capacity, which can be correlated to the increased accessibility of the pores and thus to the increased wettability and after thermal treatment. ${ }^{64}$ This also is a result of the increased $\mathrm{C}-\mathrm{O}$ and C-O-R contents (see XPS) and is backed by the now appearing quinone/hydroquinone redox couple at around $0.5 \mathrm{~V}$ vs. RHE.

After soaking, the double layer capacity increases further, and the quinone/hydroquinone redox couple becomes even more pronounced, which is in good agreement with the aforementioned additional activation due to the sulfuric acid treatment.

Due to the much higher current density compared to the other treatment methods and to increase visibility, the current densities for the aged felt in Figures $12 \mathrm{a}$ and $12 \mathrm{~b}$ are reduced by a factor of 0.5 .

The electrochemical ageing treatment results in the highest double layer capacity and a visible, but more separated quinone/hydroquinone redox couple. This can be explained by an increased surface area due to roughening and an increased $\mathrm{O} / \mathrm{C}$ ratio compared to the activated sample. Furthermore, a slightly tilted cyclic voltammogram could indicate side reaction at low potentials (hydrogen evolution) and is also visible in the voltammograms in the vanadium electrolyte (see Figure 10a).

GFD4.6EA.-Figure 10b shows the cyclic voltammogram in the vanadium electrolyte for the PAN based GFD4.6EA and Figure 11b shows the corresponding peak separation $\triangle \mathrm{E}$ and the peak current ratio $\mathrm{I}_{\mathrm{pc}} / \mathrm{I}_{\mathrm{pa}}$. The thermal treatment leads to a reduced peak separation, while $\mathrm{I}_{\mathrm{pc}} / \mathrm{I}_{\mathrm{pa}}$ basically stays the same. This decrease of $\Delta \mathrm{E}$ is in good agreement with XPS: volatile contaminants are removed, leading to a lower overall oxygen content and thus the reversibility increases, and the content of single-bonded oxygen is increased, leading to a reduced $\mathrm{sp}^{2} / \mathrm{sp}^{3}$ ratio. Raman also shows an increasing $\mathrm{I}_{\mathrm{D}} / \mathrm{I}_{\mathrm{G}}$ ratio, which indicates an increased number of defects. Looking at the cyclic voltammogram in sulfuric acid in Figure 12b, an increase in the double layer capacity is visible, as well as a slight appearance of the quinone/hydroquinone redox couple. This again can be explained by the increase of accessible pores after thermal treatment.

Both, soaking in sulfuric acid and electrochemical ageing increase $\Delta \mathrm{E}$, the $\mathrm{O} / \mathrm{C}$ ratio, and bring $\mathrm{I}_{\mathrm{pc}} / \mathrm{I}_{\mathrm{pa}}$ closer to unity. While soaking decreases the $\mathrm{sp}^{2} / \mathrm{sp}^{3}$ because of the increasing C-OR and C-H content, electrochemical ageing reduces the $\mathrm{sp}^{3}$ content resulting in a high $\mathrm{sp}^{2} / \mathrm{sp}^{3}$ ratio. For soaking, the cyclic voltammogram in Figure $10 \mathrm{~b}$ has a very similar shape like the non-activated material, but an increased reduction peak, which leads to a reduced $\mathrm{I}_{\mathrm{pc}} / \mathrm{I}_{\mathrm{pa}}$ ratio and correlates to the increased content of C-OR. A high content of C-H, which won't take part in the reaction but also can't support it, is also reflected in the increased $\mathrm{I}_{\mathrm{D}} / \mathrm{I}_{\mathrm{G}}$ ratio, which indicates an increased number of defects. This also leads to a very low thermal stability, as TGA-MS shows. Cyclic voltammetry in sulfuric acid (Figure 12b) shows an increase in the double layer capacity, a more pronounced appearance of the quinone/hydroquinone redox couple, as well as an indication of an increased hydrogen evolution, which shows in the increased absolute current densities at low potentials.

Similar effects can be seen for electrochemical ageing with even smaller peak separation, although XPS shows a significant difference in surface structure: the $\mathrm{sp}^{3}(\mathrm{C}-\mathrm{OR}, \mathrm{C}-\mathrm{H})$ content is reduced strongly, while $\operatorname{sp}^{2}(\mathrm{C}=\mathrm{C}, \mathrm{C}=\mathrm{O})$ increases, where also Raman shows more graphitic domains. In the cyclic voltammogram in sulfuric acid (Figure 12b) we observe a highly increased double layer capacity due to electrochemical oxidation and roughening. This structural change in surface can also be seen in SEM images in Figure 1. This shows that precursor has a huge effect on which type of carbon-oxygen bonds affect the electrochemical activity of graphitized felts. The occurrence of side reactions should also be considered.

KFD2.5EA.-The carbonized felt, KFD2.5EA, shows a rather sluggish reaction in a pristine state, as it is shown in the cyclic voltammograms in Figure 10c and Figure 12c. It has a peak separation of $\Delta \mathrm{E}$ $=0.679 \mathrm{~V}$ and a peak current ratio $\mathrm{I}_{\mathrm{pc}} / \mathrm{I}_{\mathrm{pa}}=1.36$, with a high influence of side reactions, as has been reported before. ${ }^{67}$ Unfortunately, after thermal treatment, the cyclic voltammograms of the felts flatten and virtually no electrochemical activity could be detected. This may be explained by the reduced oxygen content during thermal treatment, the mainly double bonded oxygen after soaking, and the particularly high $\mathrm{sp}^{2} / \mathrm{sp}^{3}$ ratio after electrochemical ageing.

\section{Conclusions}

In this current study, the influence of thermal treatment, chemical ageing and electrochemical ageing has been investigated on commercially available Rayon (GFA6 EA) and PAN based (GFD 4.6 EA, KFD 2.5 EA) carbon felts from SGL carbon.

We found significant differences in how the surface composition, thermal stability and electrochemical behavior is affected by different treatment methods. XPS results showed that thermal treatment reduces the overall surface oxygen content from around $25 \%$ to $19 \%$ for graphitized felts and from $30 \%$ to $19 \%$ for carbonized felts. The content of single bonded oxygen increased for graphitized felts, which resulted in a decrease of the $\mathrm{sp}^{2} / \mathrm{sp}^{3}$ and $\mathrm{C}=\mathrm{O} / \mathrm{C}-\mathrm{O}$ ratios. Here, the Rayon-based GFA6EA was more affected, than the PAN-based GFD4.6EA, with an increase of the C-O content of $13 \%$ and $9 \%$, respectively. The PAN also showed a very high $\mathrm{sp}^{2} / \mathrm{sp}^{3}$ ratio of 15.16 before thermal treatment. For the carbonized felt type (KFD2.5EA), thermal treatment lead to a decreased thermal stability with a mass loss of over $20 \%$ at $600^{\circ} \mathrm{C}$ and furthermore, highly reduced the electrochemical activity due to the strongly reduced overall oxygen content and increased $\mathrm{C}=\mathrm{O}$ and $\mathrm{C}=\mathrm{C}$ contents by $12 \%$ and $4 \%$, respectively. Soaking increased the surface oxygen content of all felts to around $30 \%$ due to the oxidizing nature of sulfuric acid and even further increased the electrochemical reversibility of Rayon based carbon felts with a $\Delta \mathrm{E}$ of $0.6 \mathrm{~V}$ and $\mathrm{I}_{\mathrm{pc}} / \mathrm{I}_{\mathrm{pa}}$ of nearly 1 . This correlated to the high content of single bonded oxygen species (70\%) combined with an increased $\mathrm{sp}^{2} / \mathrm{sp}^{3}$ ratio (4.05 to 5.89). Generally, the double layer capacity increased for both, GFA6EA and GFD4.6EA, increase with thermal treatment and soaking in a similar extent, where electrochemical ageing massively increases it due to additional roughening. The quinone/hydroquinone peaks appear at both graphitized felts after thermal treatment and are still present after soaking or electrochemical ageing but are slightly more separated for the thermally treated and soaked and less separated for the aged PAN-based GFD4.6EA, compared to the Rayon-based GFA6EA felts. The surface of the carbonized felt KFD2.5EA on the other hand consisted of mainly double bonded after soaking ( $89 \% \mathrm{C}=\mathrm{C}$ content) and showed particularly high $\mathrm{sp}^{2} / \mathrm{sp}^{3}$ ratio of 21.37 after electrochemical ageing. Furthermore, TGA-MS showed that soaking and electrochemical ageing lead to a much lower thermal stability for all felt types. The electrochemical activity of this felt gets highly reduced after thermal treatment, soaking or electrochemical ageing. It was also noteworthy that electrochemically aged samples are more prone to side reactions. With the utilized treatment methods, we can show that the carbonized felt KFD2.5EA will certainly not withstand the harsh environment of an operating VRFB, whereas the graphitized felts GFA6EA and GFD4.6EA are much more resistant to the induced stress. Comparing these two graphitized felts, the electrochemical performance of the Rayon based GFA6EA was even increased by the soaking in sulfuric acid, whereas the PAN based GFD4.6EA were less affected by the severe, potential induced stress. Based on this characterization study, we suggest a superior performance of graphitized carbon felts as cathode material in VRFB in 
general and a slight advantage of PAN over Rayon based carbon felts, especially at high oxidizing conditions, such as further charging at a relatively high state of charge.

This work contributes to a better understanding of the role of the precursor material and the pre-treatment (carbonization and graphitization) and how they affect the properties of electrode materials in a VRFB. Furthermore, it provides a - to this extent not yet available - comprehensive overview of commercially available carbon felts by SGL and characterizes the effects of several treatment methods by an extensive variety of methods, such as SEM, TGA-MS, Raman, XPS and electrochemical measurements.

\section{Acknowledgments}

This work was supported by the Impuls- und Vernetzungsfonds der Helmholtz Gesellschaft (Young Investigator Group project VH-NG616). We would like to kindly thank Dr. Thomas Diemant for the XPS measurements and Marlou Keller for the TGA-MS measurements. This work contributes to the research performed at CELEST (Center for Electrochemical Energy Storage Ulm-Karlsruhe).

\section{ORCID}

R. Banerjee (1D https://orcid.org/0000-0002-3646-1904

Z. Jusys (D https://orcid.org/0000-0003-3970-5799

R. Zeis (D) https://orcid.org/0000-0001-8379-0578

\section{References}

1. X. Luo, J. Wang, M. Dooner, and J. Clarke, Appl. Energy, 137, 511 (2015).

2. C. Minke and T. Turek, J. Power Sources, 376, 66 (2018).

3. G. Kear, A. A. Shah, and F. C. Walsh, Int. J. Energy Res., 36, 1105 (2012).

4. F. Díaz-González, A. Sumper, O. Gomis-Bellmunt, and R. Villafáfila-Robles, Renew. Sustain. Energy Rev., 16, 2154 (2012).

5. M. Skyllas-Kazacos, J. Electrochem. Soc., 133, 1057 (1986).

6. P. Leung et al., RSC Adv., 2, 10125 (2012)

7. A. Z. Weber et al., J. Appl. Electrochem., 41, 1137 (2011).

8. O. Nibel et al., J. Electrochem. Soc., 164, A1608 (2017).

9. C. Minke, U. Kunz, and T. Turek, J. Power Sources, 342, 116 (2017).

10. A. Bhattarai et al., J. Power Sources, 341, 83 (2017).

11. Q. Xu, T. S. Zhao, and C. Zhang, Electrochim. Acta, 142, 61 (2014).

12. X. Ke, J. M. Prahl, J. I. D. Alexander, and R. F. Savinell, J. Power Sources, 384, 295 (2018).

13. M. Yue, Q. Zheng, H. Zhang, X. Li, and X. Ma, AIChE J., 64, 782 (2017).

14. Q. Wang, Z. G. Qu, Z. Y. Jiang, and W. W. Yang, Appl. Energy, 213, 293 (2018).

15. S. K. Park et al., Electrochim. Acta, 116, 447 (2014).

16. T. Davies and J. Tummino, $C, \mathbf{4}, 8(2018)$.

17. I. Mustafa et al., Carbon N. Y., 131, 47 (2018)

18. I. Taurino, S. Carrara, M. Giorcelli, A. Tagliaferro, and G. De Micheli, Surf. Sci., 606, 156 (2012).

19. P. Han et al., Energy Environ. Sci., 4, 4710 (2011).
20. L. Wei, T. S. Zhao, G. Zhao, L. An, and L. Zeng, Appl. Energy, 176, 74 (2016).

21. J. Friedl, C. M. Bauer, A. Rinaldi, and U. Stimming, Carbon N. Y., 63, 228 (2013).

22. H. J. Lee, D. Kil, and H. Kim, J. Electrochem. Soc., 163, A2586 (2016).

23. Z. He, L. Shi, J. Shen, Z. He, and S. Liu, Int. J. Energy Res., 39, 709 (2015).

24. H. Zhang-Xing, L. Jian-Lei, H. Zhen, and L. Su-Qin, J. Inorg. Mater, 30, 779 (2015).

25. Z. He, Y. Jiang, Y. Li, L. Wang, and L. Dai, Int. J. Energy Res., 42, 1625 (2018).

26. Z. He et al., Electrochim. Acta, 259, 122 (2018).

27. A. M. Schwenke et al., J. Power Sources, 335, 155 (2016).

28. D. Dixon et al., J. Power Sources, 332, 240 (2016).

29. W. H. Wang and X. D. Wang, Electrochim. Acta, 52, 6755 (2007).

30. J. Shen, S. Liu, Z. He, and L. Shi, Electrochim. Acta, 151, 297 (2015).

31. B. Li et al., Nano Lett., 14, 158 (2014).

32. K. J. Kim et al., Chem. Commun., 48, 5455 (2012).

33. A. W. Bayeh et al., ACS Sustain. Chem. Eng., 6, 3019 (2018).

34. B. Sun and M. Skyllas-Kazacos, Electrochim. Acta, 37, 1253 (1992).

35. A. M. Pezeshki, J. T. Clement, G. M. Veith, T. A. Zawodzinski, and M. M. Mench, J. Power Sources, 294, 333 (2015).

36. J. N. Noack and J. Tübke, ECS Trans., 25, 235 (2010)

37. S. Zhong, C. Padeste, M. Kazacos, and M. Skyllas-Kazacos, J. Power Sources, 45, 29 (1993)

38. R. Schweiss, A. Pritzl, and C. Meiser, J. Electrochem. Soc., 163, A2089 (2016).

39. H. Fink, J. Friedl, and U. Stimming, J. Phys. Chem. C, 120, 15893 (2016).

40. A. M. Pezeshki, R. L. Sacci, G. M. Veith, T. A. Zawodzinski, and M. M. Menchd, J. Electrochem. Soc., 163, X13 (2016).

41. I. Derr et al., J. Power Sources, 325, 351 (2016).

42. H.-S. Choo et al., J. Power Sources, 185, 740 (2008).

43. H. Liu, Q. Xu, C. Yan, and Y. Qiao, Electrochim. Acta, 56, 8783 (2011)

44. S. Maass, F. Finsterwalder, G. Frank, R. Hartmann, and C. Merten, J. Power Sources, 176, 444 (2008).

45. I. Derr, A. Fetyan, K. Schutjajew, and C. Roth, Electrochim. Acta, 224, 9 (2017).

46. D. S. Aaron et al., J. Power Sources, 206, 450 (2012).

47. M. G. George et al., J. Electrochem. Soc., 164, F695 (2017).

48. J. Langner, J. Melke, H. Ehrenberg, and C. Roth, ECS Trans., 58, 1 (2014).

49. P. Han et al., Carbon N. Y., 49, 693 (2011).

50. S.-K. Sze, N. Siddique, J. J. Sloan, and R. Escribano, Atmos. Environ., 35, 561 (2001).

51. T. P. Mernagh, R. P. Cooney, and R. A. Johnson, Carbon N. Y., 22, 39 (1984).

52. A. Cuesta, P. Dhamelincourt, J. Laureyns, A. Martínez-Alonso, and J. M. D. Tascón, Carbon N. Y., 32, 1523 (1994).

53. J. Langner et al., J. Power Sources, 321, 210 (2016).

54. D. Yang et al., Carbon N. Y., 47, 145 (2009).

55. G. Ilangovan and K. Chandrasekara Pillai, Langmuir, 13, 566 (1997)

56. A. C. Ferrari and D. M. Basko, Nat. Nanotechnol., 8, 235 (2013).

57. A. Jorio et al., Phys. Status Solidi Basic Res., 247, 2980 (2010).

58. F. Tuinstra and J. L. Koenig, J. Chem. Phys., 53, 1126 (1970).

59. K. Haubner et al., ChemPhysChem, 11, 2131 (2010).

60. M. Park, Y. J. Jung, J. Kim, H. il Lee, and J. Cho, Nano Lett., 13, 4833 (2013).

61. D. A. C. Brownson and C. E. Banks, The Handbook of Graphene Electrochemistry, p. 1, Springer London, London, (2014).

62. J. H. Park, J. J. Park, O. O. Park, C. S. Jin, and J. H. Yang, J. Power Sources, 310, 137 (2016).

63. M. R. Tarasevich, V. A. Bogdanovskaya, and N. M. Zagudaeva, J. Electroanal. Chem. Interfacial Electrochem., 223, 161 (1987).

64. K. Kinoshita, Carbon: Electrochemical and Physicochemical Properties, Wiley, (1988).

65. L. C. Colmenares, A. Wurth, Z. Jusys, and R. J. Behm, J. Power Sources, 190, 14 (2009).

66. S. Haydar et al., Carbon N. Y., 38, 1297 (2000).

67. J. H. J. J. Park, J. H. J. J. Park, O. O. Park, C. S. Jin, and J. H. Yang, J. Power Sources, 310, 137 (2016) 